The Effect of Stakes in Distribution Experiments

\author{
by \\ Jeffrey Carpenter \\ Eric Verhoogen \\ Stephen Burks
}

December 2003

MID D LEBURY COLLEGE ECONO MICS D ISCUSSION PAPER NO. 03-28

\begin{abstract}
DEPARTMENT OF ECONOMICS
MIDDLEBURY COLLEGE

MIDDLEBURY, VERMO NT 05753
\end{abstract}

http:/ / www.middlebury.edu/ econ 


\title{
The Effect of Stakes in Distribution Experiments
}

\author{
Jeffrey Carpenter ${ }^{*} \quad$ Eric Verhoogen ${ }^{\ddagger} \quad$ Stephen Burks ${ }^{\S}$
}

December 3, 2003

\begin{abstract}
We replicate previous results showing that stakes do not affect offers in the Ultimatum Game and show that stakes also have no effect on allocations in the Dictator Game. Both results are robust to the inclusion of demographic factors.

JEL codes: C91, Z13

Keywords: ultimatum game, dictator game, stakes, fairness, altruism
\end{abstract}

\section{Introduction ${ }^{1}$}

It is conventional for social scientists to pay subjects for their participation in behavioral research, however economists look at the issue of pay differently from the others. While psychologists and sociologists use compensation to get subjects to show up, economists believe that participants consider choices more carefully when there are financial consequences. Our purpose is to discuss an experiment that examines the effects of increasing the stakes in two well-known economic games, the ultimatum game and the dictator game each played for low $(\$ 10)$ and high $(\$ 100)$ stakes.

In the ultimatum game (UG) two people, a first-mover (proposer) and a second-mover (responder) are allocated a sum of money, which they can share if they can come to an agreement. Responders decide whether to accept or reject offers from the proposers. Accepted offers are implemented but rejected offers result in both players receiving nothing. Because the proposer is allowed to make a take-it-or-leave-it offer, and because the proposer knows any reasonable

\footnotetext{
*Department of Economics, Middlebury College, jpc@middlebury.edu.

${ }^{\dagger}$ Corrresponding author.

${ }^{\ddagger}$ Department of Economics, University of California, Berkeley, everhoog@econ.berkeley.edu.

$\S$ Economics \& Management, University of Minnesota, Morris, svburks@mrs.umn.edu.

${ }^{1}$ We thank Julia Assael and Marla Weinstein for research assistance, Laura Burks for data assistance, and the MacArthur Foundation for financial support. In addition Carpenter acknowledges the National Science Foundation (SES-CAREER 0092953) and Verhoogen acknowledges the MacArthur Foundation's cost of inequality network.
} 
responder will accept even a little money rather than rejecting an offer, subgame perfection dictates the proposer should receive nearly all the money. The dictator game (DG), is a variant of the UG in which second-players get whatever they are allocated. That is, second-players can not veto the proposal. Notice, removing the veto power of the second-mover appears to change the game substantially, but the subgame perfect allocation does not change noticeably; dictators receive all the money instead of nearly all the money.

The experiments we discuss below are unique for three reasons. First, we report an experiment that raises the stakes in the DG. Second, but no less important, we replicate earlier studies that have raised the stakes in the UG. Third, we collect demographic control data to econometrically test the robustness of any stake effects.

\section{Related Work}

In their review, Camerer and Hogarth (1999) summarize the effect of stakes on behavior in economic experiments. Overall, their analysis shows that stakes change average behavior little, but games with larger (or non-zero) stakes tend to generate data with less variance. However, when there are differences, the differences are in the direction of standard theory because games with no stakes (i.e. participants only receive a show-up fee) or low stakes are often afflicted with hypothetical biases that cause players to be less risk averse and more generous. The authors specifically note that bargaining games such as the UG show little change in average behavior when stakes are increased, but participants in dictator games tend to be less generous when the stakes are increased from zero to five dollars.

In Hoffman et al. (1996) 98 pairs played the UG for either $\$ 10$ or $\$ 100$. The authors found that increasing the stakes had no statistically significant effect on the offers. However, they did find that as the stakes increased the frequency of rejected offers decreased significantly indicating that responders were more willing to accept smaller fractions of a larger pie. The stylized facts of the Hoffman et al. data have also been replicated in extremely high stakes games conducted with Indonesian students (Cameron (1999)), with French and Romanian students (Munier and Zaharia (2003)), and with Slovakian students (Slonim and Roth (1998)). In her study, Cameron was able to raise the stakes to $\mathrm{Rp200,000} \mathrm{( \$ 92.59)} \mathrm{which,} \mathrm{at} \mathrm{the} \mathrm{time,} \mathrm{represented} \mathrm{three} \mathrm{times} \mathrm{the} \mathrm{aver-}$ age monthly expenditures of the participants. Similarly, Munier and Zaharia conducted both low stakes $(\$ 7)$ games and very high stakes games $(\$ 360)$ and Slonim and Roth raised the stakes to nearly $\$ 50$. Consistent with prior UGs, the data from these studies revealed modal offers of 50-50 and an average offers of $42 \%$ in Indonesia, $43 \%$ in France, $37 \%$ in Romania and $43 \%$ in Slovakia. ${ }^{2}$ As in Hoffman et al., all these experiments showed that, while the stakes had

\footnotetext{
${ }^{2}$ The means for the Munier and Zaharia and Slonim and Roth data are at the end of ten rounds of bargaining.
} 
little effect on proposers' offers, responders reduced their willingness to reject any given offer as the stakes increased.

In low stakes games it appears that proposers correctly estimate that low offers will be rejected. By backward induction, this expectation causes players to pick offers close to the level that is payoff maximizing which is slightly less than half the pie (see Prasnikar and Roth (1992)). At high stakes, proposers either miss-calculate the probability that low offers will be rejected and offer too much or are more sensitive to risk. This second hypothesis is consistent with Binswanger (1980), and Holt and Laury (2002) who report that players become more risk averse at high stakes.

There has been much less work on stakes in the DG. To begin, Sefton (1992) finds the average allocation to the second-mover drops by approximately half when going from no stakes to $\$ 5$ stakes. However, this comparison is confounded by the hypothetical bias. Forsythe et al. (1994) conduct all their experiments at positive stakes but the difference in the stakes is small. They show that the mean allocation falls from $48 \%$ in a no stakes game to between $28 \%$ or $23 \%$ depending on whether the stakes are $\$ 5$ or $\$ 10$, but the difference between the $\$ 5$ game and the $\$ 10$ game is not significant.

\section{Methods}

We conducted experiments with Middlebury College students using a set of instructions similar to Forsythe et al. (1994). We gathered a total of 79 observations: 19 \$10UG, 20 \$100UG, 19 \$10DG, and 21 \$100DG. Participants filled out a demographic survey and then were given written instructions and told to follow along as one of the experimenters read aloud. After any questions were answered, we flipped a coin to see whether the people with odd or even participant numbers would become first-movers. Second-movers were taken to a different room and waited silently. First-movers were asked to choose between eleven discrete allocations. In the UG, responders circled either Accept or Reject. When all the responders were finished, the proposal forms were collected and the responders were paid, one at a time. In the DG, recipients were allowed to see what had been allocated to them, they were paid, and then the first-movers were paid.

\section{Examining Stakes}

Figure 1 graphs histograms of behavior from our four sessions. One can compare the two upper histograms of the games at $\$ 10$ stakes to the two lower games at $\$ 100$ stakes to see that there appears to be a slight "flattening" effect of stakes. In the DG there is one anomalous transfer of the entire $\$ 10$ and in the UG we see some reallocation of offers from half to one-third of the pie at high stakes. 


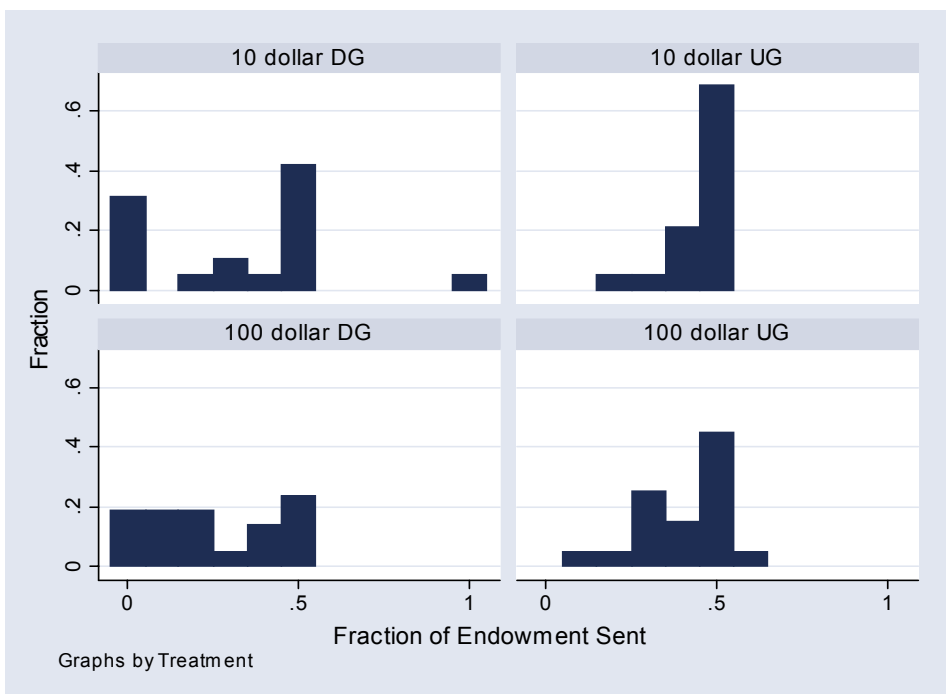

Figure 1 - Histograms of first-mover behavior in the two stakes treatments.

However, this flattening effect is not statistically significant. Table 1 presents summary statistics on the fraction of the surplus allocated to the second-mover. In the UG the mean drops slightly as the stakes increase but, as shown in Table 2, this difference is insignificant. ${ }^{3}$ Based on these uncontrolled tests (column 2), we conclude that, stakes do not seem to affect offers in our UG. Lastly, only one of a combined 39 UG offers was rejected which precludes any sort of regression analysis of second-mover behavior - there is no variance to account for.

\begin{tabular}{lcccc}
\hline \multicolumn{5}{c}{ Table 1 - Summary Statistics of First-Mover Behavior } \\
\hline & 10 Dollar UG & 100 Dollar UG & 10 Dollar DG & 100 Dollar DG \\
Observations & 19 & & & \\
Mean Allocation & 0.45 & 0.41 & 0.33 & 21 \\
Median Allocation & 0.50 & 0.45 & 0.40 & 0.25 \\
Minimum Allocation & 0.20 & 0.10 & 0.00 & 0.20 \\
Maximum Allocation & 0.50 & 0.60 & 1.00 & 0.00 \\
Standard Deviation & 0.08 & 0.13 & 0.27 & 0.50 \\
Rejection Rate & 0 of 19 & 1 of 20 & - & - \\
Highest Rejected Offer & NA & 0.10 & - & - \\
\hline
\end{tabular}

As is common in the DG (e.g. Forsythe et al. (1994), Hoffman et al. (1994)), the distribution of offers lies to the left of the equal split, but allocations are still mostly positive. The mean allocation in the $\$ 10 \mathrm{DG}$ seems higher than in

\footnotetext{
${ }^{3}$ We employ two tests to check for differences in the distributions. The first test is the Wilcoxon test for differences in central tendencies and the second test is the KomogorovSmirnov test for differences in the cumulative distributions of allocations.
} 
the $\$ 100 \mathrm{DG}$, but this is partially driven by an outlier in the $\$ 10 \mathrm{DG}$ where one dictator gave away all $\$ 10$. In fact, the first column of Table 2 illustrates that stakes do not appear to have a significant effect on behavior in the DG (with or without the outlier).

\begin{tabular}{lcc}
\hline \multicolumn{2}{c}{ Table 2 - Difference Tests for First-Mover Behavior } \\
\hline & 100 Dollar DG & 100 Dollar UG \\
10 Dollar DG & $\mathrm{Z}=0.86, \mathrm{p}=0.39$ & - \\
& $\mathrm{KS}=0.24, \mathrm{p}=0.53$ & - \\
10 Dollar DG (minus outlier) & $\mathrm{Z}=0.60, \mathrm{p}=0.55$ & \\
& $\mathrm{KS}=021 ., \mathrm{p}=0.72$ & $\mathrm{Z}=1.20, \mathrm{p}=0.23$ \\
& - & $\mathrm{KS}=0.24, \mathrm{p}=0.50$ \\
\hline
\end{tabular}

\section{Controlling for Demographics Effects}

Table 3 presents summary statistics for the demographics we gathered from our first-movers. In addition to standard demographics on age, sex, years of schooling, family income, ethnicity, and number of siblings, we also had participants fill out a personality scale called the Mach scale first developed in Christie and Geis (1970) and assessed their risk preferences using a hypothetical binary lottery question. The Mach scale consists of twenty statements drawn from Machiavelli's The Prince to which subjects are asked to agree or disagree. Those who tend to agree with the Machiavellian statements are called "high Machs," and those who disagree "low Machs." ${ }^{4}$ We included the Mach scale with the goal of controlling for variations in predispositions toward engaging in manipulative behaviors. In previous work, Meyer (1992) found evidence suggesting high Machs are less likely to reject low offers, while Gunnthorsdottir, McCabe, and Smith (2000), using a modified trust game, found high Machs reciprocated less.

\footnotetext{
${ }^{4}$ The Mach scale is designed to capture three components of an individual's personality: the extent to which a subject has a cynical view of human nature, believing that others are not trustworthy; the willingness of a subject to engage in manipulative behaviors; and the extent of the subjects' concern (or lack thereof) with conventional morality [Christie and Geis (1970)]. Scores are summed over the 20 questions, and a constant of 20 is added, to generate a measure that ranges between 40 and 160, with a neutral score of 100 .
} 


\begin{tabular}{l|ccc}
\hline \multicolumn{4}{c}{ Table 3 - Summary Statistics for Participant Demographics } \\
\multicolumn{1}{c}{ (FIrST-MOvers in BOTH Games) } \\
\hline Variable & $\mathrm{n}$ & Mean & Standard Deviation \\
\hline Mach Score & 79 & 93.76 & 15.16 \\
Age & 79 & 19.48 & 1.27 \\
Female & 79 & 0.53 & 0.53 \\
Schooling (years) & 79 & 13.39 & 1.15 \\
Family Income & 77 & 149,221 & 96,556 \\
Non-white & 79 & 0.14 & 0.35 \\
Number of Siblings & 79 & 1.51 & 1.41 \\
Risk Aversion & 79 & 6.41 & 2.16 \\
\hline
\end{tabular}

To control for the possibility that players' risk attitudes affect their offers in the UG and because there is evidence that risk attitudes depend on the size of the stakes, we employed the following simple binary lottery scenario. Each participant was told to imagine that $\mathrm{s}(\mathrm{he})$ had a lottery ticket and that the ticket's payoff ( $\$ 0$ or $\$ 10$ ) was determined by the flip of a coin. Participants were then asked how much someone else would have to offer before they would sell the ticket. The average response was $\$ 6.41$ indicating that our subjects revealed a slight preference for risk in this hypothetical scenario.

Because our dependent variable is ordinal, we use the ordered logit estimator. We also cluster errors by experimental session to account for any idiosyncrasies associated with running the sessions. Table 4 presents our results. Beginning with the UG, we see that adding demographic controls does not change the fact that stakes do not influence proposals. There are, however, a few interesting correlations. As one might expect, high Machs offer significantly less as do people who are more risk seeking. Additionally, our non-white participants offer more and people with more siblings offer less. While significant, most of the effects are small. A standard deviation increase in each of the significant regressors changes the odds of offering nothing in the following way: Mach score $(+1 \%)$, risk loving $(+1 \%)$, non-white $(-1 \%)$, siblings $(+1 \%)$. Finally, while proposer risk attitudes are associated with offers, there does not seem to be a differential effect of risk in the high stakes treatment - the interaction is not significantly different from zero. 


\begin{tabular}{|c|c|c|c|}
\hline & (1) & (2) & (3) \\
\hline & $\mathrm{UG}$ & DG & DG - outlier \\
\hline \multirow[t]{2}{*}{ Stakes } & -0.01 & $-0.07^{* * *}$ & -0.03 \\
\hline & $(0.03)$ & $(0.02)$ & $(0.04)$ \\
\hline \multirow[t]{2}{*}{ Mach Score } & $-0.04^{* * *}$ & -0.004 & -0.02 \\
\hline & $(0.01)$ & $(0.04)$ & $(0.04)$ \\
\hline \multirow[t]{2}{*}{ Age } & -0.21 & -0.26 & -0.32 \\
\hline & $(0.20)$ & $(1.02)$ & $(0.92)$ \\
\hline \multirow[t]{2}{*}{ Female } & 0.13 & -0.13 & -0.06 \\
\hline & $(0.31)$ & $(0.14)$ & $(0.15)$ \\
\hline \multirow[t]{2}{*}{ Schooling (years) } & 0.06 & 0.004 & 0.08 \\
\hline & $(0.65)$ & $(0.66)$ & $(0.55)$ \\
\hline \multirow[t]{2}{*}{ Family Income } & $4.51 \mathrm{e}-06$ & $-5.73 \mathrm{e}-06^{* * *}$ & $-6.88 \mathrm{e}-06^{* * *}$ \\
\hline & $(5.64 \mathrm{e}-06)$ & $(7.00 \mathrm{e}-07)$ & $(2.25 \mathrm{e}-06)$ \\
\hline \multirow[t]{2}{*}{ Non-white } & $3.83^{* *}$ & 0.06 & -0.16 \\
\hline & $(1.95)$ & $(0.95)$ & $(1.11)$ \\
\hline \multirow[t]{2}{*}{ Number of Siblings } & $-0.41^{* * *}$ & -0.47 & -0.38 \\
\hline & $(0.07)$ & $(0.33)$ & $(0.25)$ \\
\hline \multirow[t]{2}{*}{ Risk Loving } & $-0.26^{* * *}$ & $-1.22^{* * *}$ & $-0.65^{*}$ \\
\hline & $(0.09)$ & $(0.17)$ & $(0.38)$ \\
\hline \multirow[t]{2}{*}{ Stakes $\times$ Risk Loving } & 0.001 & $0.01^{* * *}$ & 0.005 \\
\hline & $(0.003)$ & $(0.003)$ & $(0.006)$ \\
\hline $\mathrm{N}$ & 37 & 40 & 39 \\
\hline Pseudo $\mathrm{R}^{2}$ & 0.11 & 0.13 & 0.09 \\
\hline
\end{tabular}

In the DG we see that stakes seem to matter when we include controls, but this is really due to our outlier who gave everything in the $\$ 10 \mathrm{DG}$. If we exclude this observation (column 3), we see that stakes do not matter in the DG either. What is also interesting is that DG allocations are significantly affected by family income and risk attitudes and that these marginal effects are more substantial. A standard deviation increase in family income and risk loving increases the probability of offering nothing by $11 \%$ and $23 \%$, respectively.

\section{Bibliography}

Binswanger, H. (1980). Attitudes toward risk: Experimental measurement in rural India. American Journal of Agricultural Economics 62(August): 395-407.

Camerer, C. and R. Hogarth (1999). The effects of financial incentives in experiments: A review and capital-labor-production framework. Cal Tech Social Science Working Paper 1059.

Cameron, L. (1999). Raising the stakes in the ultimatum game: Experimental evidence from Indonesia. Economic Inquiry 37(1): 47-59.

Christie, R. and F. Geis (1970). Studies in Machiavellianism. New York, Academic Press. 
Forsythe, R., J. Horowitz, N. E. Savin and M. Sefton (1994). Fairness in simple bargaining experiments. Games and Economic Behavior 6: 347-369.

Hoffman, E., K. McCabe, J. Shachat and V. Smith (1994). Preferences, property rights, and anonymity in bargaining games. Games and Economic Behavior 7: 346-380.

Hoffman, E., K. McCabe and V. Smith (1996). On expectations and the monetary stakes in ultimatum games. International Journal of Game Theory 25: 289-301.

Holt, C. and S. Laury (2002). Risk aversion and incentive effects. American Economic Review 92(5): 1644-1655.

Meyer, H.-D. (1992). Norms and self-interest in ultimatum bargaining: The prince's prudence. Journal of Economic Psychology 13: 215-232.

Munier, B. and C. Zaharia (2003). High stakes and acceptance behavior in ultimatum bargaining: A contribution from an international experiment. Theory and Decision 53: 187-207.

Prasnikar, V. and A. Roth (1992). Considerations of fairness and strategy: Experimental data from sequential games. Quarterly Journal of Economics 107(3): 865-888.

Sefton, M. (1992). Incentives in simple bargaining games. Journal of Economic Psychology 13: 263-276.

Slonim, R. and A. Roth (1998). Learning in high stakes ultimatum games: An experiment in the Slovak republic. Econometrica 66(3): 569-596. 